\title{
Exploring Structural Relationships in Attracting and Retaining International Students in STEM for Sustainable Development of Higher Education
}

\author{
Dian-Fu Chang ${ }^{1, *}$, Kuo-Yin Lee ${ }^{2}$ and Chun-Wen Tseng ${ }^{3}$ \\ 1 Department of Education and Futures Design, Tamkang University; 140626@mail.tku.edu.tw \\ 2 Doctoral Program of Advanced Education Leadership and Technology Management, Tamkang University; \\ 810710037@gms.tku.edu.tw \\ 3 Doctoral Program of Advanced Education Leadership and Technology Management, Tamkang University; \\ a6051222@ms25.hinet.net \\ * Correspondence: 140626@mail.tku.edu; 886-2-2621-5656; No. 151, Yingzhuan Rd., Tamsui Dist., New Taipei \\ City 251301, Taiwan
}

\begin{abstract}
Attracting and retaining international students has been widely discussed in higher education settings. Increasing the number of international students has become an indispensable strategy for national and global competition. This study focuses on effective strategies and international students' issues regarding satisfaction in the most popular STEM (science, technology, engineering, and mathematics) programs. We designed a structural equation modeling (SEM) method to determine the effect of institutional mediation between push factors and satisfaction factors for the development of better strategies by which to attract and retain international students. Taking Taiwan as an example, this study employed a self-designed questionnaire to collect data: 485 degree-seeking international students in STEM programs were invited and successfully participated in this study during spring 2021. IBM SPSS 26 and AMOS 26 (Analysis of Moment Structure) were used to carry out the data analysis. We employed reliability, factor, and SEM analyses. This study assumed that the impact of push factors can be modified by institutional situations and result in international students' satisfaction with their learning and environment and regarding migration policy. The results revealed that the predictors, mediation, and criteria were significant at the 0.05 or 0.01 levels. The findings suggest that push factors impact international students' satisfaction when using the institutional leadership and international strategy. The results of the bootstrap with a generalized least square method showed that the SEM model fit in 2000 bootstrap samples. The effect of institutional mediation can provide useful information for STEM programs to boost their future recruitment and retention strategies. This study provides an innovative approach to the detection of issues among international students in specific programs. These findings can enrich our knowledge regarding attracting and retaining global students in higher education settings.
\end{abstract}

Keywords: higher education; international students; leadership and governance; SEM; STEM; sustainable development; sustainability

\section{Introduction}

International student mobility has become a global phenomenon. According to an OECD report, international student mobility has been expanding in the last two decades. There were 6.1 million students worldwide who crossed a border to pursue their studies abroad in 2019, more than twice the number recorded for 2007. This implies the number of international students grew on average by 5.5\% per year between 1998 and 2019 in higher education settings [1]. Most countries realize that highly educated, mobile students may be an important source of income and can have an impact on economic performance and innovation systems [2]. There are various countries that have attracted a large number of international students to increase the pool of qualified labor, for example, Australia, 
New Zealand, the United Kingdom, and the United States [1]. Attracting and retaining international students has become an indispensable strategy for national and global competition. It is a crucial strategy for the sustainable development of higher education. According to Rumbley and Altbach's argument, understanding the relationship between national and global competition is key to comprehending the nature of higher education internationalization in the $21^{\text {st }}$ century [3]. Uncertainty and rapid changes in technology have challenged employment, for example, new jobs created in the fourth industrial revolution and AI replacing related job opportunities [4]. This development trend has encouraged more students to participate in science, technology, engineering, and mathematics (STEM) programs. In this regard, related strategies might drive international policy, focusing on learning and teaching in high-tech or innovative technology areas. STEM might become crucial fields for students to achieve their purposes. This is why we selected STEM as our research target. This study focuses on international students in STEM in order to investigate what they want and how they perceive their study journey.

There are various studies addressing international students' issues, for example, lockdown issues impacting international students during the pandemic [5-7], mobility issues affecting international students [8,9], and what works for attracting and retaining international students $[10,11]$. The findings of previous studies did not confirm whether there were statistical relationships between the context of origins and institutional situations in the destination country. Since the contextual factors are various, study groups in specific STEM programs might confront complex institutional situations. We assumed that the factors in situational dimensions will impact specific international students, which might play a crucial role in their study journey. Since this study targeted international students in STEM, it needs a more rigorous research design in order to explore whether a meaningful learning process was achieved among the international students.

During this period, Taiwanese higher education was challenged by serious demographic and environmental changes. For example, the gross enrollment ratio (GER) in higher education exceeded 50\% in 1999, indicating that the universal system had arrived in Taiwan as per Trow's definition [12]. In recent decades, the capacity of higher education has expanded rapidly. The GER in higher education hit $83.88 \%$ in 2013 , which was higher than that of most other Asian countries [13,14]. Taiwanese higher education can accommodate a large of capacity students, including international students. Meanwhile, the expanded higher education system has been confronted with declining enrolment in last decade. Obviously, the number of new born babies in Taiwan has decreased from 328,461 in 1974 to 196,973 in 2016, showing a 40 percent decrease according to data from the Ministry of Interior [15]. Under this declining trend, many higher education institutes have found themselves confronted with a serious shortage in student recruitment [16]. The Ministry of Education set an internationalized goal of attracting 130,000-140,000 inbound students by 2020 [17]. One reason for this initiative is that the government was trying to face the challenge of declining enrolment trends. Moreover, due to the COVID-19 pandemic, higher educational institutes around the world closed down or partially closed down to control the spread during this period. These measures in higher education could change international student mobility intentions in the coming years [18]. Therefore, attracting more international students might become an optimal strategy for overcoming uncertain threats and issues of over-expansion in the higher education system. Even though the STEM programs still attracted many students, we worried that the pandemic and the issue of decline might impact enrollment temporarily or in the long run.

This study argues that the expansion of higher education might shift the landscape of international students in STEM programs. We propose a structural model by which to verify the causal relationships of push factors, institutional mediation variables, and satisfaction variables. The results will confirm which relationship works. The findings can promote institutes' capabilities to recruit and retain international students in STEM. In addition, the research design and findings can enrich the knowledge related to attracting and retaining international students in similar higher education settings. For these purposes, this study explored the following research questions: 
a. What are the influential factors that lead to international students' satisfaction in STEM programs?

b. Can STEM programs make differences to their institutional mediation in attracting and retaining international students?

c. What kinds of structural models can interpret the phenomena of international students in STEM programs?

The rest of the paper is presented as follows: First, we present a literature review, which includes analysis of the factors that impact international students' satisfaction. Second, the methodology section is presented, including instruments, samples, hypotheses, and statistical analyses. Third, the results are displayed, including the result of factor analysis, reliability analysis, structural equation modeling (SEM), and the bootstrap method. Finally, a conclusion is drawn, and we provide some suggestions for attracting and retaining international students for sustainable higher education.

\section{Literature Review}

The internationalization of higher education has been assumed to be a vehicle for a two-way flow of knowledge across national, cultural, linguistic, and perspective boundaries to promote social justice and global citizenship for sustainable development [19]. The traditional role of higher education has been shown to be transforming regarding the movement of students' global mobility. In this section, we focus on the growth of STEM in higher education, related theories to interpret the phenomena of students' global mobility, factors related to students' satisfaction, and what kinds of institutional mediation can help.

\subsection{Growth of STEM Programs}

The growth of STEM has become a prevalent phenomenon. For example, Australia

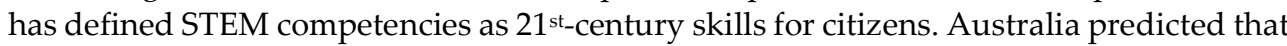
future workers will spend more than twice as much time on job tasks requiring science, math, and critical thinking than today. STEM education can complement the development of 21st-century skills, for example, critical thinking, creativity, cultural awareness, collaboration, and problem solving [20]. As the world of work changes, we will need to prepare or enhance our skills accordingly. STEM programs have become attractive in the tertiary education level. In the United States, there are various studies indicating that offering a specialized STEM program in a high school may boost the number of students majoring in a college's STEM programs [21-22]. These intentions indicate the importance of STEM and the global trend of future development. Novel or high technological growth has driven the STEM programs to become the most popular programs on campus.

Higher education has expanded rapidly in recent decades in Taiwan. A related quality assurance policy has also been initiated. During recent decades, integrated STEM education in higher education has been initiated in the Teaching Excellence Project and Higher Education Sprout Project (HESP). These initiatives have been integrated into the related measures in secondary education, for example, problem-centered learning, inquiry-based leaning, design-based learning, and cooperative learning for specific programs [23]. The government plans to invest TWD 83.6 billion over five years in the HESP, and this project will extend to the next five years. The project encourages universities to develop their own characteristics and innovative teaching techniques for students' learning. [24]. In addition, a global Taiwan sub-project of HESP provided extra money to fund the selected universities for their internationalization. According to the Essential Science Indicators (ESI) rankings in 2020,33\% of Taiwanese universities have entered the list of the world's top one percent of research institutes [25]. Of course, this is not only in the quantitative dimension, as the quality of these institutes has reached a world-class level within higher education systems. Significantly, the number of international students studying degree programs, language learning programs, and short-term exchanges in Taiwan increased to 98,247 in 2020, while the international student enrollment was only 30,509 in 
2007 [26]. Additionally, the number of international students participating in STEM has shown an increase. The growth of STEM has led to this field becoming attractive for domestic and international students. High technology has driven Taiwan to move upwards, and various universities have established AI-related programs or professional colleges. This trend might attract more international students studying in the STEM fields.

\subsection{Interpretation of Push-Pull and Spatial Theory}

Reviewing the student mobility literature, we found Ravenstein's push-pull theory as a traditional approach by which to explain international student flow [27-29]. Lee focused on migration issues with positive and negative signs representing push and pull factors, respectively. Between the places of origin and destinations, impact factors may include environmental factors, economic and social factors, and intervening obstacles [30]. Previous studies have addressed various issues of international student mobility, for example, Souto-Otero et al. indicated positive individual motivations for studying abroad [31], and some studies have discussed the obstacles embedded in student mobility [32,33]. Mazzarol and Soutar argued that, when deciding to study internationally, students might go through four distinct stages: clarifying their intention to study abroad, choosing a country in which to study, selecting a type of institute, and choosing a city [34]. To interpret the mobile phenomena, we can classify the push factors into a negative domain, which international students confront in their original countries. Whereas, the pull factors can be interpreted as an attractive domain, which may be provided by the destination countries.

Moreover, there are several overlapping perspectives across the spatial, mobility, and network theories [35]. For example, Massey [36] and Soja [37,38], post-structural spatial scholars, emphasized how space is constructed and changed by human activity within it, and how human activity is altered and shaped by spatial arrangements, such as the concept of the local and the global. Larsen recommended an analysis using spatial, network, and mobility theories to achieve internationalization in higher education [35]. The spatial theory provides a holistic approach by which to analyze global mobility phenomena. In this sense, the spatial theory may provide a window through which to view complex student global mobility. When international students integrate their learning and life with domestic students on campus, the phenomenon may accelerate the effect of "internationalization at home" [39].

\subsection{Factors Impacting Satisfaction}

Previous studies have indicated that life satisfaction is a significant indicator by which to evaluate how well international students have adjusted to their new studying situation [40,41]. Studies have shown that exposure to an unfamiliar environment can cause anxiety, confusion, and depression, leading to insomnia and physical illness [42]. These experiences have been observed among international students experiencing loneliness or isolation [43-45]. After overcoming negative factors, they will be able to enjoy the journey of their study. The major task for international students is learning on campus. Successful learning experiences can bring about international students' satisfaction, which may include the program design, teaching and learning process, and reasonable assessment. Leaning satisfaction could be a crucial factor for the retention of international students. Moreover, institutional mediation has become an influential factor impacting international students' travel decisions, for example, leadership in institutes, internationalized strategies, the learning environment, and travel restrictions for international students. Beyond the institutional level, a government's policy can make differences, for example, China has initiated a "Study in China" program to increase the number of inbound international students [46], and Taiwan has a scholarship for excellent international students. In addition, friendly migration policies could be an influential factor for attracting international students. Recently, the government has released the migration policy for international students in STEM fields. Selected STEM graduate students could get permanent 
residency and work in high technological companies. Even though there are complaints that universities have become corporate organizations that seek to generate profit [47], it is not surprising that international education is increasingly being integrated into migration marketing strategies, such as those pertaining to permanent residency [48]. It is clear that useful policies may increase international students' satisfaction in the destination.

\section{Method}

This study was conducted using the following procedures. First, we employed selfdesigned questionnaires as instruments to collect the data. Second, we proposed an SEM model to test what works for attracting and retaining international students in STEM programs. Third, we presented the characteristics of the target samples. Finally, we addressed the related verification process to confirm our evidence from the data.

\subsection{Instruments}

We designed three measurements to test the structural model. In this study, the latent variables included push factors, institutional mediation, and satisfaction. There were 15 observed items falling under the three domains: push factors with four items, institutional mediation with three items in institutional leadership and four items in international strategies, and satisfaction with four items. To collect data on the perception of international students in STEM programs, all items in the questionnaire were designed using a 5-point Likert scale, ranging from 1 (strongly disagree) to 5 (strongly agree). The 3 domains and 15 observed items are listed as follows (Table 1).

Table 1. Definitions of observed items.

\begin{tabular}{ll}
\hline Domains/observed items & Definitions of observed items \\
\hline Push factors/ & It is difficult to find employment opportunities in my country \\
PS1: & I have experienced poor living conditions in my country \\
PS2: & For family reasons, I have decided to study abroad \\
PS3: & In my country, I have political reasons to study abroad \\
PS4: & \\
Institutional mediation/ & I experienced that my university has strong leadership for student affairs \\
Institutional leadership & My university's policy is indifferent to the treatment of international students \\
IL1: & I experienced that my university has a collegial decision-making mechanism \\
IL2: & I experienced a clear international strategy on campus \\
IL3: & My university provides various learning opportunities or funding for international students \\
International strategies & My university encourages recruitment of international students \\
IS1: & My university encourages international students to attend conferences abroad and provides \\
IS2: & funding support \\
IS3: & \\
IS4: & I am satisfied with my learning process \\
Satisfaction/ & I am satisfied with my campus environment \\
Learning: & I am satisfied with the academic program that I participated in \\
Environment: & I am satisfied with the migration policy in the destination country \\
Academic_friendly: &
\end{tabular}

\subsection{A Testing Model for SEM}

Considering that the push factors, institutional leadership and international strategies, and satisfaction may exist in a structural relationship, we developed null hypotheses regarding international students' perceptions on these variables in the SEM. We assumed that institutional mediation may play a significant role in the structural relationship. In this study, four null hypotheses for testing in SEM were listed, as follows: 
Hypothesis 1 (H1): There is no relationship between push factors and institutional mediation variables;

Hypothesis 2 (H2): There is no relationship between push factors and satisfaction variables;

Hypothesis 3 (H3): There is no relationship between institutional mediation and satisfaction variables;

Hypothesis 4 (H4): Push factors will not, through institutional mediation variables, impact satisfaction variables.

If the statistical significances reject the null hypotheses, the result will confirm that the causal relationships exist in this model. Since there were three latent variables, this was a mediation model design with a structural equation model. If the mediation effect exists, the indirect effect will be significantly larger than that of the direct effect. Institutional mediation was assigned as a mediation effect in the model. Figure 1 shows the theoretical framework for detecting the effect of push factors, institutional mediation, and satisfaction.

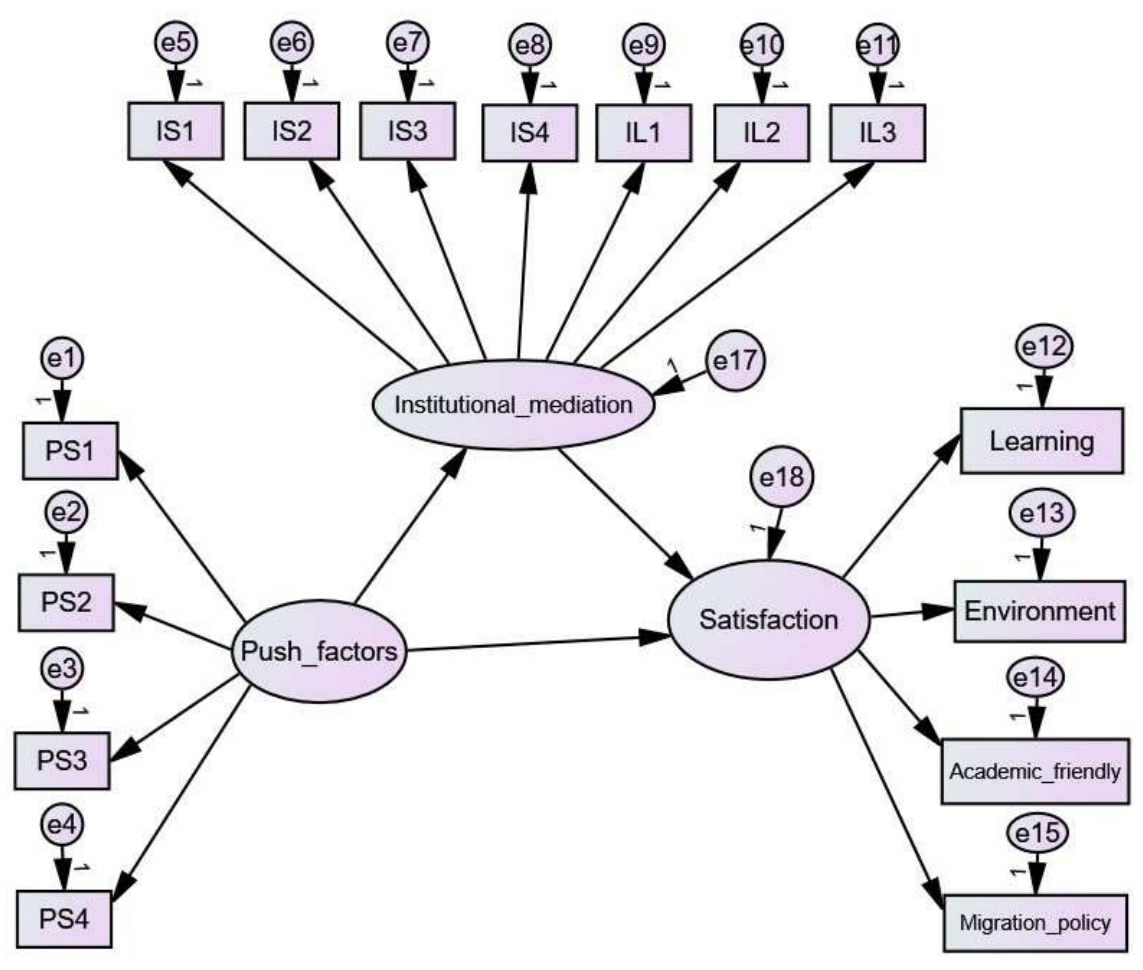

Figure 1. The proposed model for testing in SEM.

\subsection{Research Targets and Samples}

According to the statistics of international students from the Ministry of Education, the number of international degree students in Taiwan was 52,714 in 2020 [25]. This research targeted international students majoring in STEM. Since the international students were enrolled in different higher education institutes, this survey used an online sampling technique during spring in 2021. All the participants participated voluntarily. If they felt uncomfortable, they were able to withdraw immediately. After deleting uncompleted questionnaires and non-degree seekers, we received 485 valid questionnaires from international students in STEM programs. The distribution of the samples showed that 55.7\% were male and $44.3 \%$ were female. A total of $27.8 \%$ were studying for a bachelor's degree, 
$36.5 \%$ for a master's degree, and 35.7\% for a doctoral degree in STEM. Most of the international students in STEM were from Asian countries (76.9\%); this figure is also reflected in the similar distribution of international students in Taiwan. The details of the distribution of the international students in the samples are listed in Table 2.

Table 2. The distribution of 485 samples in STEM.

\begin{tabular}{|c|c|c|c|}
\hline \multicolumn{2}{|c|}{ Classification } & \multirow{2}{*}{$\begin{array}{c}\text { Frequency } \\
270\end{array}$} & \multirow{2}{*}{$\begin{array}{c}\text { Percent } \\
55.7\end{array}$} \\
\hline Condon & Male & & \\
\hline Gender & Female & 215 & 44.3 \\
\hline \multirow{6}{*}{ Origin } & Asia & 373 & 76.9 \\
\hline & Oceania & 13 & 2.7 \\
\hline & Africa & 16 & 3.3 \\
\hline & Europe & 14 & 2.9 \\
\hline & America & 42 & 8.7 \\
\hline & China & 27 & 5.6 \\
\hline \multirow{3}{*}{ Degree-seeking } & Bachelor's & 135 & 27.8 \\
\hline & Master's & 177 & 36.5 \\
\hline & Doctoral & 173 & 35.7 \\
\hline
\end{tabular}

\subsection{Data Transformation and Statistical Analyses}

After considering the data structure, we employed IBM SPSS 26 and AMOS 26 (Analysis of Moment Structure) to conduct the data analyses in this study. To verify the structural relationship, we conducted a reliability analysis, factor analysis, and SEM in order to obtain meaningful evidence. First, reliability was used to estimate the internal consistency of the instrument before moving the data sets into the SEM; a Cronbach's alpha $>0.6$ can be used as an index of convergent validity for a measure to fit SEM [49]. Second, we considered that the factor loadings of the observed items should be larger than 0.50 $[50,51]$. Third, the overall model fit in SEM was assessed using the common goodness-offit indices, including Chi-square minimum (CMIN), ratio of Chi-square to degrees of freedom $(\chi 2 / \mathrm{df}<5.0)$, number of distinct parameters (NPAR), goodness-of-fit index (GFI > $0.90)$, adjusted goodness-of-fit index (AGFI > 0.90), parsimonious goodness-of-fit index (PGFI > 0.50), root-mean-square residual (RMR <0.08), and Akaike Information Criterion (AIC $=\chi 2-2 \times \mathrm{df}$; it tended to be smaller) [52-55]. If the estimated values in the SEM model fit the ideal criteria, this demonstrates an acceptable goodness-of-fit between the hypothetical model and the sample data. In this case, the hypothetical model was supported.

In addition, we followed the following steps to estimate the effect of mediation. First, we used type I error and statistical power to evaluate the effect of mediation [56-58]. Second, we followed Shrout and Bolger's recommendation to apply the bootstrap method to estimate the effect of mediation [59]. The bootstrap method is a process of using resampling to achieve the mean of the effect of mediation ( $\left.r 11^{*} \beta 1\right)$. We used AMOS to conduct the bootstrapping. In this study, the bootstrap sample was larger than the original dataset. We selected the number of bootstrap samples as 2000. In the mediating effect test, $Z$ = point estimate/standardized error (SE). When $Z>1.96$, this represents that there is a mediation effect between the variables. When performing the bootstrap, we selected percentile confidence intervals or bias-corrected confidence intervals at $95 \%$ confidence level as justified criteria. In the bootstrap process, the histogram provided an estimate of the shape of the distribution of the sample mean. Based on the histogram, we examined how much the mean varied across the target number of bootstrap samples.

\section{Results}

In this section, we demonstrate how the international students' data in STEM programs were transformed to fit the SEM model and how the proposed SEM model was 
verified. First, we display the descriptive statistics of the push factors, institutional mediation, and satisfaction. Then, we present the reliability and factorial loadings of the measures. Finally, the results of the SEM testing and bootstrapping are addressed.

\subsection{Descriptive Statistics of Push Factors, Institutional Mediation, and Satisfaction}

Table 3 displays the descriptive statistics of the observed items for push factors, institutional mediation, and satisfaction. Regarding each factor with the different observed items, this study calculated the mean of the factor with its number of observed items. The means of the push factors, institutional mediation, and satisfaction are 2.95, 3.82, and 3.69, respectively. Based on Kline's definition, when the value of skewness is larger than \pm 3 , it belongs to absolute skewness [60]. In this study, we found the values of skewness and kurtosis to fit the requirements of normal distribution. The results of the descriptive statistics suggest that the data can be transformed and estimated as parameters in SEM.

Table 3. Descriptive statistics of push factors, institutional mediation, and satisfaction.

\begin{tabular}{llrrrr}
\hline Observed items & $\mathrm{N}$ & Mean & Std. D. & Skewness & Kurtosis \\
\hline Push factors & & & & & \\
$\quad$ PS1 & 485 & 2.79 & 1.106 & 0.106 & -0.687 \\
PS2 & 485 & 3.64 & 1.112 & -0.574 & -0.335 \\
PS3 & 485 & 2.81 & 1.148 & 0.088 & -0.810 \\
PS4 & 485 & 2.58 & 1.108 & 0.310 & -0.552 \\
Institutional mediation & & & & & \\
IL1 & 485 & 3.93 & 0.834 & -0.622 & 0.534 \\
IL2 & 485 & 3.69 & 0.815 & 0.043 & -0.443 \\
IL3 & 485 & 3.63 & 0.856 & -0.362 & 0.280 \\
IS1 & 485 & 3.87 & 0.902 & -0.711 & 0.334 \\
IS2 & 485 & 3.94 & 0.962 & -0.897 & 0.552 \\
IS3 & 485 & 4.03 & 0.783 & -0.781 & 1.159 \\
IS4 & 485 & 3.67 & 0.995 & -0.565 & 0.061 \\
Satisfaction & & & & & \\
Learning & 485 & 3.79 & 0.831 & -0.305 & -0.010 \\
Environment & 485 & 3.85 & 0.824 & -0.301 & -0.255 \\
Academic_friendly & 485 & 2.93 & 1.152 & -0.013 & -0.955 \\
$\quad$ Migration_policy & 485 & 4.01 & 0.827 & -0.584 & 0.197 \\
\hline
\end{tabular}

\subsection{Construct of Measurement}

In this study, we judged the construct of measurement for international students according to the following criteria: First, we tested the correlation of the items; second, the items should possess internal consistency (Cronbach's alpha >0.6); third, the acceptable variance is explained, and, usually, the explained variance of the variables is over $50 \%$. The construct of measurement should demonstrate that the removal of any item does not change the essential nature of the underlying construct.

First, Table 4 shows the correlation matrix of push factors, institutional mediation variables, and satisfaction variables. The results revealed that most items with Pearson's correlation were significant at the 0.05 level, which fit in order to test them in the SEM. We considered whether the selected items had high correlations or not. When the selected items with high correlations measure an essentially similar concept, this could lead to a multi-collinearity problem, and one or more items need to be eliminated. The result indicated that there was no such problem in the selected items. In this study, the mean of the inter-item correlations was 0.414 . 
Table 4. Correlation matrix of push factors, institutional mediation, and satisfaction.

\begin{tabular}{|c|c|c|c|c|c|c|c|c|c|c|c|c|c|c|}
\hline Observed items & PS1 & PS2 & PS3 & PS4 & IL1 & IL2 & IL3 & IS1 & IS2 & IS3 & IS4 & L. & E. & A. \\
\hline PS1 & 1.000 & & & & & & & & & & & & & \\
\hline PS2 & 0.405 & & & & & & & & & & & & & \\
\hline PS3 & 0.250 & 0.273 & & & & & & & & & & & & \\
\hline PS4 & 0.292 & 0.311 & 0.414 & & & & & & & & & & & \\
\hline IL1 & -0.020 & 0.189 & 0.047 & 0.072 & & & & & & & & & & \\
\hline IL2 & 0.011 & 0.141 & 0.009 & -0.009 & 0.331 & & & & & & & & & \\
\hline IL3 & 0.080 & 0.214 & 0.110 & 0.121 & 0.471 & 0.403 & & & & & & & & \\
\hline IS1 & 0.048 & 0.178 & 0.098 & 0.075 & 0.639 & 0.348 & 0.543 & & & & & & & \\
\hline IS2 & 0.067 & 0.124 & 0.136 & 0.071 & 0.415 & 0.332 & 0.474 & 0.528 & & & & & & \\
\hline IS3 & 0.046 & 0.165 & 0.083 & 0.070 & 0.421 & 0.303 & 0.433 & 0.503 & 0.507 & & & & & \\
\hline IS4 & 0.091 & 0.165 & 0.105 & 0.113 & 0.456 & 0.295 & 0.499 & 0.489 & 0.512 & 0.504 & & & & \\
\hline Learning & -0.095 & 0.105 & 0.022 & 0.075 & 0.435 & 0.246 & 0.381 & 0.424 & 0.329 & 0.318 & 0.343 & & & \\
\hline Environment & -0.086 & 0.208 & 0.031 & 0.064 & 0.379 & 0.315 & 0.427 & 0.433 & 0.344 & 0.311 & 0.347 & 0.634 & & \\
\hline Academic_friendly & 0.105 & 0.099 & 0.186 & 0.132 & -0.072 & -0.048 & -0.035 & 0.005 & -0.060 & -0.073 & 0.019 & -0.141 & -0.044 & \\
\hline Migration policy & 0.006 & 0.175 & 0.058 & 0.134 & 0.267 & 0.211 & 0.388 & 0.350 & 0.297 & 0.309 & 0.279 & 0.287 & 0.350 & -0.047 \\
\hline
\end{tabular}

Second, the reliability analysis for the measurement showed that Cronbach's alpha was 0.788 , and Cronbach's alpha based on the standardized items was 0.809 among the 15 items. On the push-factor scale, the total variance explained for the four items was $49.325 \%$, and Cronbach's alpha was 0.657 . On the institutional mediation scale, the total variance explained for the seven items was $53.106 \%$, and Cronbach's alpha was 0.656 . On the satisfaction scale, the total variance explained for the four items was $47.228 \%$, and Cronbach's alpha was 0.370 . This was not satisfactory for the satisfaction scale. After deleting Academic_friendly, we found that the total variance explained for the three items on the satisfaction scale was up to $62.266 \%$, and Cronbach's alpha was 0.688 . The result of the satisfaction scale suggested that the three-item construct was better than the four-item construct.

Third, the related information for Cronbach's alpha of an item deleted is displayed in Table 5. We found that Academic_friendly was abnormal. It also demonstrated that the deletion was corrected.

Table 5. Items' total statistics and information for Cronbach's alpha if the item is deleted.

\begin{tabular}{lrrrrr}
\hline Observed items & $\begin{array}{c}\text { Scale mean if } \\
\text { item is deleted }\end{array}$ & $\begin{array}{c}\text { Scale variance if } \\
\text { item is deleted }\end{array}$ & $\begin{array}{c}\text { Corrected item- } \\
\text { total correlation }\end{array}$ & $\begin{array}{c}\text { Squared multiple } \\
\text { correlation }\end{array}$ & $\begin{array}{c}\text { Cronbach's alpha } \\
\text { if item is deleted }\end{array}$ \\
\hline PS1 & 50.38 & 48.099 & 0.192 & 0.252 & 0.795 \\
PS2 & 49.53 & 45.134 & 0.395 & 0.292 & 0.777 \\
PS3 & 50.36 & 46.648 & 0.274 & 0.230 & 0.788 \\
PS4 & 50.58 & 46.653 & 0.290 & 0.250 & 0.786 \\
IL1 & 49.24 & 45.622 & 0.528 & 0.482 & 0.767 \\
IL2 & 49.47 & 47.469 & 0.368 & 0.227 & 0.778 \\
IL3 & 49.54 & 44.617 & 0.605 & 0.460 & 0.761 \\
IS1 & 49.29 & 44.018 & 0.621 & 0.562 & 0.759 \\
IS2 & 49.22 & 44.446 & 0.538 & 0.430 & 0.764 \\
IS3 & 49.14 & 46.159 & 0.517 & 0.398 & 0.769 \\
IS4 & 49.50 & 43.854 & 0.563 & 0.426 & 0.762 \\
Learning & 49.38 & 46.760 & 0.424 & 0.470 & 0.775 \\
Environment & 49.31 & 46.220 & 0.479 & 0.491 & 0.771 \\
Academic_friendly & 50.24 & 50.542 & 0.024 & 0.087 & 0.811 \\
Migration_policy & 49.16 & 47.057 & 0.399 & 0.229 & 0.776 \\
\hline
\end{tabular}

\subsection{Testing of the structural equational model}

The result of SEM, with the generalized least squares method (GLS), indicated that the CMIN was 185.604, and the degree of freedom was 71 in the model. In this study, the value of $\chi^{2} / \mathrm{df}$ was $2.614\left(\chi^{2}=185.604 ; \mathrm{df}=71\right)$; this implied a good fit $(2.614<3.00)$ of the 
testing model. The result of SEM revealed that the NPAR (the number of parameters) was 34 , implying that the model was defined as moderately complex. The results revealed that the model-fit indices (GFI, AGFI, PGFI, and RMR) exceeded the acceptance levels (GFI = $0.945>0.90$, AGFI $=0.921>0.90, \mathrm{PGFI}=0.657>0.50, \mathrm{RMR}=0.0630<0.08)$. In this study, the value of AIC tended to be smaller (AIC = 253.604). Based on the results of the SEM, this study has shown the recommended values for the model fit. The model suggests that the significant standardized coefficients are push factors $\rightarrow$ institutional mediation (0.232) and institutional mediation $\rightarrow$ satisfaction (0.732). The mediation effect of push factors through institution to satisfaction was 0.169 . Table 6 displays the standardized coefficients in the paths and $p$-values. The results revealed that there were three null hypotheses that were rejected, which implied that a causal relationship existed in the model.

Table 6. The estimated and standardized coefficients and significance of p-values.

\begin{tabular}{ccccc}
\hline Hypotheses & & & Standardized & $\boldsymbol{p}$ \\
\hline H1: Institutional mediation & $\leftarrow$ & Push factors & 0.232 & $*$ \\
H2: Satisfaction & $\leftarrow$ & Push factors & -0.030 & - \\
H3: Satisfaction & $\leftarrow$ & Institutional mediation & 0.732 & $*$ \\
H4: Satisfaction $\leftarrow$ Institutional mediation & $\leftarrow$ & Push factors & 0.169 & $*$ \\
\hline
\end{tabular}

The results of the null hypotheses tests are as follows:

Hypothesis 1 (H1): There is no relationship between push factors and institutional mediation variables (rejected);

Hypothesis 2 (H2): There is no relationship between push factors and satisfaction variables (accepted);

Hypothesis 3 (H3): There is no relationship between institutional mediation variables and satisfaction variables (rejected);

Hypothesis 4 (H4): Push factors will not, through international mediation variables, impact satisfaction variables (rejected).

Based on the verified information, the findings suggested that the institutional mediation effect existed in this model. The details of the structural relationships in SEM are displayed in Figure 2.

\subsection{Testing of effect of mediation}

The correlation coefficients of the latent variables are listed in Table 7. They reflect that the $r$ between the push factors and satisfaction was 0.105; the $r$ between the push factors and institutional mediation was 0.184 , and the $r$ between institutional mediation and satisfaction was 0.596 . The results revealed that the predictor, mediation, and criteria were significant at the 0.05 or 0.01 level.

Table 7. Correlation coefficients of latent variables in the proposed model.

\begin{tabular}{llrr}
\hline Latent variables & Correlation & Push factors & Satisfaction \\
\hline Push factors & Pearson correlation & 1 & \\
& Sig. (2-tailed) & & \\
Satisfaction & Pearson correlation & $0.105^{*}$ & \\
& Sig. (2-tailed) & 0.020 & \\
Institutional mediation & Pearson correlation & $0.184^{* *}$ & $0.596^{* *}$ \\
& Sig. (2-tailed) & 0.000 & 0.000 \\
\hline
\end{tabular}

Note: ${ }^{*} \mathrm{p}<0.05 ;{ }^{* *} \mathrm{p}<0.01$ 


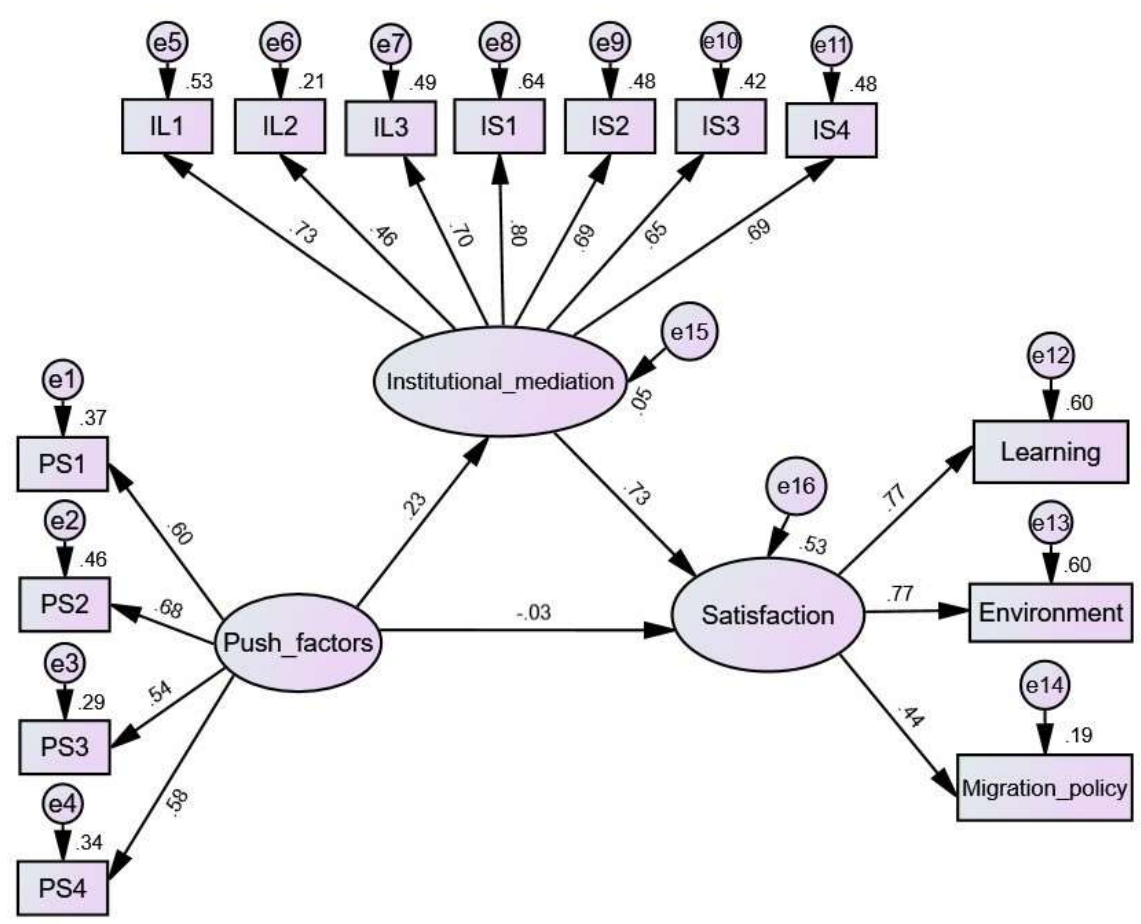

Figure 2. The results of SEM.

In the results of testing the effect of mediation, we found that the statistical power depended on both the coefficient $\mathrm{r}_{11}$ (Push factors $\rightarrow$ Institutional mediation) and $\beta_{1}$ (Institutional mediation $\rightarrow$ Satisfaction), which are significant. This fits Sobel's suggestion that calculating the coefficient ( $\left.\mathrm{r}_{11}\right)$ and $\beta_{1}$ can determine the mediation effect $\left(\mathrm{r}_{11}{ }^{*} \beta_{1}\right)$ [58]. The result of the bootstrap method with 2,000 samples showed that the effect of mediation $\left(\mathrm{r}_{11}{ }^{*} \beta_{1}\right)$ was 0.170 , and it was significant at the 0.05 level. The direct effects of institutional mediation and push factors on satisfaction were $0.732(p<0.05)$ and $-0.030(p>0.05)$, respectively. The details of the $p$-values and $95 \%$ conference intervals of percentile confidence (PC) and bias-corrected (BC) intervals are listed in Table 8 . The results revealed that the indirect effect was significant, and the values of the $95 \%$ confidence intervals with PC and $\mathrm{BC}$ did not include 0 . The findings suggest that the mediation effect of institutional mediation works in this model.

Table 8. Summarizing the estimated standardized effect of indirect, direct, and total effect with PC and BC.

\begin{tabular}{|c|c|c|c|c|}
\hline \multirow[t]{2}{*}{ Effects } & \multirow[t]{2}{*}{ Estimated } & \multirow[t]{2}{*}{ PC/BC $p$-value } & \multicolumn{2}{|c|}{$95 \%$ confidence interval } \\
\hline & & & PC & BC \\
\hline \multicolumn{5}{|l|}{ Indirect effect } \\
\hline $\begin{array}{l}\text { Push factors } \rightarrow \text { Institutional mediation } \\
\rightarrow \text { Satisfaction }\end{array}$ & 0.170 & $0.006 / 0.009$ & $0.057 \sim 0.277$ & $0.049 \sim 0.271$ \\
\hline \multicolumn{5}{|l|}{ Direct effect } \\
\hline Institutional mediation $\rightarrow$ Satisfaction & 0.732 & $0.001 / 0.001$ & $0.624 \sim 0.827$ & $0.623 \sim 0.826$ \\
\hline Push factors $\rightarrow$ Satisfaction & -0.030 & $0.659 / 0.681$ & $-0.172 \sim 0.128$ & $-0.170 \sim 0.130$ \\
\hline Total effect & 0.14 & $0.138 / 0.154$ & $-0.058 \sim 0.334$ & $-0.061 \sim 0.332$ \\
\hline
\end{tabular}

The histogram shows the distribution of the $B$ quantities with 2,000 samples, $C_{G L S}\left(\hat{\boldsymbol{\alpha}}_{b}, \mathbf{a}_{b}\right), \quad b=1, \ldots, B$ (see Figure 3).

|--------------------- 


\begin{tabular}{|lll|}
\hline & 200.22 & $\mid *$ \\
& 209.24 & $\mid * * * *$ \\
& 218.25 & $\mid * * * * * * * * * * * *$ \\
& 227.27 & $\mid * * * * * * * * * * * * * * * * * * * *$ \\
& 236.28 & $\mid * * * * * * * * * * * * * * * * * * * *$ \\
& 245.30 & $\mid * * * * * * * * * * * * * * *$ \\
& 254.31 & $\mid * * * * * * * * *$ \\
$\mathrm{~N}=2000$ & 263.33 & $\mid * * * * * *$ \\
$\mathrm{Mean}=237.83$ & 272.34 & $\mid * * *$ \\
$\mathrm{~S} . \mathrm{e} .=.37$ & 281.36 & $\mid *$ \\
& 290.37 & $\mid *$ \\
& 299.39 & $\mid *$ \\
& 308.40 & $\mid *$ \\
& 317.42 & $\mid$ \\
& 326.43 & $\mid *$ \\
& & $\mid-------------------$ \\
\hline
\end{tabular}

Figure 3. Generalized least square discrepancy (implied vs. population).

\section{Discussion}

Previous studies argued attracting and retaining more international students could provide advantages in future, for example, increasing the revenue of higher education institutes, upgrading innovative systems, and promoting economic performance $[1,2]$. Among the study fields in higher education, we found STEM has become crucial fields for achieving this purpose. We selected STEM programs as research targets, it assumed the STEM are attractive fields. If we can recruit more international students, it may release the threat of declining enrollment in the target higher education system $[15,16]$. Moreover, this study emphasized the issues of international students in STEM, for example lockdown impacting international students during the COVID-19 pandemic [5-7]. During the post-pandemic era, global mobility could be a new barrier for international students planning their study journey. What works for attracting and retaining international students has also challenged the previous arguments [37-39]. This study provided a framework to verify the relationships among negative push factors, institutional leadership \& international strategies, and satisfaction in STEM. Previous studies have addressed the importance of attracting and retaining international students $[33,34,46]$. This study intended to move the theoretical arguments to evidence-based research practices.

The result of bootstrapping in SEM demonstrated that the effect of mediation existed in our proposed model. Considering the samples are limited, the bootstrap method could be an optimal solution to project the reliability of research to a relative large group. This study found the international students in STEM did not suffer serious negative push factors in their original countries. Table 3 revealed push factors perceived by the international students in STEM are relative low. But the push factors did not link to satisfaction directly in the testing of SEM. This phenomenon reflected that higher education institutes can exert strong institutional mediation. Based on the findings, we may suggest that higher education institutes can reinforce their institutional mediation measures for international students, for example, reviewing their institutional leadership and international strategies as our proposed framework annually.

This study found that most of international students satisfied with their learning situation, campus environment, and daily life. If migration policy allowed the graduated international students from STEM fields to get permanent residency, it will encourage more international students engaged in STEM programs. This study confirmed this argument. While the migration policy is a policy intervention controlled by government level, it may not be extended to other study fields. 


\title{
6. Conclusions
}

This study aimed to obtain effective institutional strategies for international students and their satisfaction in STEM programs. According to the research design and verification of the structural equation modeling, we found that the effect of institutional mediation between the push factors and satisfaction factors provided useful information for attracting and retaining international students. This study proposed an innovative approach by which to detect international students' issues, not limited to STEM. The findings suggest that institutional mediation could be an influential factor that leads to international students' satisfaction. Appropriate institutional mediation, for example, institutional leadership and institutional strategies, can make a difference in the retention of international students. The SEM results demonstrated negative push factors among international students, which through effective institutional leadership and international strategies, impact their learning and environment satisfaction in STEM.

Considering that studies focusing on international students in STEM are still limited, we suggest that the testing model can be extended to wider higher education settings to explore similar issues. Since international students have become competitive resources in higher education, this design can be used to review the competition between programs in a system or in an institute for sustainable development. For further studies, we encourage comparing international students' participation in other programs as well as considering differences of gender and countries of origin in order to develop effective strategies for attracting and retaining students. Related information from further studies can promote sustainable higher education systems.

\begin{abstract}
Author Contributions: Conceptualization, Dian-Fu Chang; methodology, Dian-Fu Chang, Kuo-Yin Lee, and Chun-Wen Tseng; software, Kuo-Yin Lee, and Chun-Wen Tseng; validation, Dian-fu Chang, Kuo-Yin Lee, and Chun-Wen Tseng; formal analysis, Dian-Fu Chang; investigation, KuoYin Lee and Chun-Wen Tseng; resources, Dian-Fu Chang; data curation, Dian-Fu Chang; writingoriginal draft preparation, Dian-Fu Chang, Kuo-Yin Lee, and Chun-Wen Tseng; writing-review and editing, Dian-Fu Chang; visualization, Dian-Fu Chang; supervision, Dian-Fu Chang; All authors have read and agreed to the published version of the manuscript.
\end{abstract}

Funding: Please add: This research received no external funding.

Data Availability Statement: The data presented in this study are available on request from the corresponding author.

Institutional Review Board Statement: Not applicable.

Informed Consent Statement: Not applicable.

Acknowledgments: The authors wish to express their gratitude to the international students in STEM programs participated in the survey.

Conflicts of Interest: The authors declare no conflict of interest.

\section{References}

1. OECD. Education at a Glance: OECD Indicators; OECD Publishing: Paris, France, 2021.

2. European Migration Network. Attracting and Retaining International Students in the EU; European Migration Network: Brussels, Belgium, 2019.

3. Rumbley, L.E.; Altbach, P.G. The local and the global in higher education internationalization. In Global and Local Internationalization; Rumbley, L.E.; Altbach, P.; Eds.; Sense: Rotterdam, Netherlands, 2016; pp. 7-13.

4. Aoun, J.E. Robot-proofs: Higher Education in the Age of Artificial Intelligence; MIT Press: Boston, MA, USA, 2017.

5. Koris, R.; Mato-Díaz, F.J.; Hernández-Nanclares, N. From real to virtual mobility: Erasmus students' transition to online learning amid the COVID-19 crisis. Eur. Educ. Res. J. 2021, 20, 463-478.

6. Chang, D.F.; Chou, W.C. Detecting the institutional mediation of push-pull factors on international students' satisfaction during the COVID-19 pandemic. Sustainability 2021, 13, 11405.

7. Mok, K.H.; Xiong, W.; Ke, G.; Cheung, O.J.W. Impact of COVID-19 pandemic on international higher education and student mobility: Student perspectives from mainland China and Hong Kong. Int. J. Educ. Res. 2021, 105, 101718 
8. Xia, F.; Chang, D.-F. Forecasting student mobility flows in higher education: A case study in China. ICIC Express Lett. Part B Appl. 2021, 12, 525-532.

9. Stewart, W.H. Seoul destination: A mixed-methods study on the pull factors of inbound exchange students at a Korean university. Forum Int. Res. Educ. 2020, 6, 58-82

10. Hoffmeyer-Zlotnik, P.; Grote, J. Attracting and retaining international students in Germany. Study by the German National Contact Point for the European Migration Network (EMN). Working Paper 85 of the Research Centre of the Federal Office for Migration and Refugees; Federal Office for Migration and Refugees: Nuremberg, Germany, 2019. Available online: https://www.researchgate.net/publication/332530519_Attracting_and_retaining_international_students_in_Germany_Study_by_the_German_National_Contact_Point_for_the_European_Migration_Network_EMN (accessed on 20 December 2021).

11. Kondakci, Y. Student mobility reviewed: Attraction and satisfaction of international students in Turkey. High. Educ. 2011, 62, 573-592.

12. Trow, M. Problems in the transition from elite to mass higher education, ERIC, ED 091983, 1973. Available online: http://files.eric.ed.gov/fulltext/ED091983.pdf (assessed on 12 November 2021).

13. Chang, D.F.; Huang, Y.L. Detecting the effect of policy intervention for oversupply higher education system. ICIC Express Let., Part B Appl. 2017, 8, 1489-1495.

14. Chang, D.F. Effects of higher education expansion on gender parity: A 65-year trajectory in Taiwan. High. Educ. 2018, 76, 449466.

15. Ministry of Interior, The Main Directory of Dynamic Query Statistics 2018. Available online: http://statis.moi.gov. $\mathrm{tw} / \mathrm{micst} / \mathrm{stmain}$.jsp?sys=100 (accessed on 10 November 2021).

16. Wu, S.J.; Chang, D.F.; Hu, H. Detecting the issue of higher education over-expanded under declining enrollment times. High. Educ. Policy. 2021, 34, 747-770.

17. Chang, D.F. Implementing internationalization policy in higher education explained by regulatory control in neoliberal times. Asia Pacific Educ. Rev. 2015, 16, 603-612.

18. OECD. The State of Higher Education: One Year in to the COVID-19 Pandemic; OECD Publishing: Paris, France, 2021.

19. Handa, N. Education for Sustainability through Internationalization, Palgrave Studies in Global Citizenship Education and Democracy, 2018. Available online: https://doi.org/10.1057/978-1-137-50297-1_1 (accessed on 22 November 2021).

20. The Department of Education, Skills and Employment, Australian Government. Why is STEM important? Available online: https://www.dese.gov.au/australian-curriculum/national-stem-education-resources-toolkit/introductory-material/why-stemimportant (accessed on 17 December 2021).

21. Bottia, M.C.; Stearns, E.; Mickelson, R.K.; Moller, S. Boosting the numbers of STEM majors? The role of high schools with a STEM program. Sci. Educ. 2018, 102, 85-107. Available online: https://doi.org/10.1002/sce.21318 (assessed on 20 November 2021).

22. Means, B.; Wang, H.; Young, V.; Peters, V.L.; Lynch, S,J. STEM-focused high schools as a strategy for enhancing readiness for postsecondary STEM programs. J. of Res. in Sci. Teach. 2016, 53, 709-736.

23. Thibaut, L.; Ceuppens, S.; De Loof, H.; De Meester, J.; Goovaerts, L.; Struyf, A.; Boeve-de Pauw, J.; Dehaene, W.; Deprez, J.; De Cock, M.; Hellinckx, L.; Knipprath, H.; Langie, G.; Struyven, K.; Van de Velde, D.; Van Petegem, P.; Depaepe, F. Integrated

STEM education: A systematic review of instructional practices in secondary education. European J. of STEM Educ. $2018,3,2$.

24. MOE, Higher Education Sprout Project, 2021. Available online: https://sprout.moe.edu.tw/SproutWeb/Project/DocDownload (accessed on 10 December 2021).

25. MOE, Education in Taiwan 2021. Available online: https://stats.moe.gov.tw/files/ebook/Education_in_Taiwan/2021-2022_Education_in_Taiwan.pdf (accessed on 15 December 2021).

26. MOE, School basic information-international students enrolled in colleges and universities, 2021. Available online: https://depart.moe.edu.tw/ED4500/News_Content.aspx?n=5A930C32CC6C3818\&sms=91B3AAE8C6388B96\&s=B7F6EA80CA2F63EE (accessed on 16 December 2021)

27. Ravenstein, E.G. The laws of migration (part 1). J. of the Royal Statistical Society. 1985, 48, 167-227.

28. Ravenstein, E.G. The laws of migration (part 2). J. of the Royal Statistical Society. 1989, 52, 241-301.

29. Chang, D.F.; Chou, W.C. Detecting the institutional mediation of push-pull factors on international students' satisfaction during the COVID-19 pandemic. Sustainability. 2021, 13, 11405.

30. Lee, E. A theory of migration. Demography. 1966, 3(1), 47-57.

31. Souto-Otero, M.; Huisman, J.; Beerkens, M.; de Wit, H.; Vujić, S. Barriers to international student mobility: Evidence from the Erasmus program. Educ. Res. 2013, 41, 70-77. Available online: https:// doi.org/10.3102/0013189X12466696 (Accessed on 20 November 2021).

32. Findlay, A.M.; King, R.; Geddes, A.; Smith, F.M.; Geddes, A.; Skeldon, R. World class? An investigation of globalization, difference and international student mobility. Transactions of the Institute of British Geographers. 2012, 37, 118-131. Available online: https://doi.org/10.1111/j.1475-5661.2011.00454.x (accessed on 5 December 2021).

33. Hauschildt, K.; Gwosć, C.; Netz, N.; Mishra, S. Social and Economic Conditions of Student Life in Europe: Synopsis of Indicators/Eurostudent-V, 2012-2015. W. Bertelsmann; Verlag: Bielefeld, Germany, 2015.

34. Mazzarol, T.; Soutar, G.N. Push-pull factors influencing international student destination choice. CEMI discussion paper series, DP 0105, Centre for Entrepreneurial Management and Innovation, 2001. Available online: 
http://www.cemi.com.au/sites/all/publications/CEMI\%20DP0105\%20Mazzarol\%20and\%20Soutar\%202001.pdf (accessed on 22 June 2021).

35. Larsen, M.A. Internationalization of Higher Education: An Analysis through Spatial, Network, and Mobility Theories. Palgrave Macmillan: New York, NY, USA, 2016.

36. Massey, D. For Space. Sage: Los Angeles, CA, USA, 2005.

37. Soja, E.W. Third Space: Journeys to Los Angeles and Other Real-and-imagined Places. Blackwell, Oxford, UK, 1996.

38. Soja, E.W. Taking space personally. In The Spatial Turn: Interdisciplinary Perspective; Warf, B., Arias, S., Eds.; Routledge, London, UK, 2009; pp. 11-34.

39. Knight, J. Higher Education in Turmoil: The Changing World of Internationalization; Sage Publishers: Rotterdam, Netherlands, 2008.

40. Salimi, A. Social-emotional loneliness and life satisfaction. Procedia Soc. Behav. Sci. 2011, 29, $292-295$.

41. Yalçun, I. Social support and optimism as predictors of life satisfaction of college students. Int. J. Adv. Couns. $2011,33,79-87$.

42. Lin, J.G.; Yin, J.K. Asian international students' adjustment: Issues and program suggestions. Coll. Stud. J. 1997, 31, 473-480.

43. Russell, J.; Rosenthal, D.; Thomson, G. The international student experience: Three styles of adaption. High. Educ. 2010, 60, 235-249.

44. Sandhu, D.S. An examination of the psychological needs of the international students: Implications for counselling and psychotherapy. Int. J. Adv. Couns. 1994, 17, 229-239.

45. Sawir, E.; Marginson, S.; Deumert, A.; Nyland, C.; Ramia, G. Loneliness and international students: An Australian study. J. Stud. Int. Educ. 2008, 12, 148-180.

46. Wen, W.; Hu, D.; Hao, J. International students' experiences in China: Does the planned reverse mobility work? Int. J. Educ. Dev. 2018, 61, 204-212.

47. Maringe, F. The meanings of globalization and internationalization in HE: Findings from a world survey. In Globalization and internationalization in higher education: Theoretical, strategic and management perspectives; Maringe F., Foskett, N., Eds.; Continuum: New York, NY, USA, 2010; pp. 17-34.

48. Baas, M. The language of migration: The education industry versus the migration industry. People and Place, 2007, 15(2), 4960.

49. Blanthorne, C.; Jones-Faremer, L.A.; Almer, E.D. Why you should consider SEM: A guide getting started. Adv. Account. Behav. Res. 2006, 9, 179-207.

50. Bentler, P.M. Comparative fit indexes in structural models. Psychol. Bull. 1990, 107, 238-246.

51. Walker, S.L.; Fraser, B.J. Development and validation of an instrument for assessing distance education environments in higher education: The distance education learning environments survey (DELES). Learn. Environ. Res. 2005, 8, 308-389.

52. Loehlin, J.C. Latent Variable Models: An. Introduction to Factor, Path, and Structural Equation Analysis, 4th ed.; Lawrence Erlbaum Associate: Mahwah, NJ, USA, 2004.

53. Schumacker, R.E.; Lomax, R.G. A Beginner's Guide to Structural Equation Modeling; Lawrence Erlbaum Associate: Mahwah, NJ, USA, 2004.

54. Byrne, B.M. Structural Equation Modeling with EQS and EQS/Windows; Sage: Thousand OAKs, CA, USA, 1994.

55. Hu, L.T.; Bentler, P.M. Cutoff criteria for fit indexes in covariance structure analysis: Conventional criteria versus new alternatives. Structural Equational Modeling: A multidisciplinary J. 1999, 6, 1-55.

56. Mackinnon, D.P.; Lockwood, C.M.; Hoffman, J.M.; West, S.G.; Sheets, V. A comparison of methods to test mediation and other intervening variable effects. Psychol. Methods, 2002, 7, 83-104.

57. Barron, R.M.; Kenny, D.A. The moderator-mediator variable distinction in social psychological research: Conceptual, strategic, and statistical considerations. J. of Personality and Social Psychol. 1986, 51(6), 1173-1182.

58. Sobel, M.E. Asymptotic confidence intervals for indirect effects in structural equation models. Sociol. Methodology. 1982, 13, 290-313.

59. Shrout, P.E.; Bolger, N. Mediation in experimental and non-experimental studies: New procedures and recommendations. Psychol. Methods, 2002, 7(4), 422-445.

60. Kline, R.B. Principles and Practice of Structural Equation Modeling; Guilford: New York, NY, USA, 1988. 